\title{
Chopsticks as a Cultural Symbol in China
}

\author{
Chen Desheng \& Tang Zheng \\ Ph.D. Scholar, Department of English and Foreign Languages, Bharathiar University, Coimbatore-641046 \\ II M.A English literature, Department of English, R.V.S College of Arts \& Science, Coimbatore-641402
}

\begin{abstract}
Food is the soul of health.
On such occasions as birthday, food becomes a cultural show in today's society. When food from one country becomes in another, it leads a kind of cultural exchange. China has a rich tradition of food culture which has spread around the world.

As a society develops, food culture too evolves resulting in variety. Each geographical location makes its own food with unique taste and flavor. Sour, sweet, bitter and hot are the tastes of various food items. Apart from being food, they tell us about the people who make it, their culture and nation.

The tools which people use to eat are not only tools, but also symbols, tokens of that culture. The practice of using chopsticks has existed from ancient times among the East Asians, especially the Chinese.

Made of different materials like gold, silver, copper, wood and bamboo, the chopsticks also express the artistic and aesthetic sensibility of the Chinese people. History tells us that the different colors, sizes and materials of chopsticks have specific meanings. They may stand for position, treasure, luck and so on.

This paper attempts to study the importance of chopsticks as a dominant cultural symbol in China. It brings out their representative values. The role played by chopsticks in customs, rituals and ceremonies in China is also highlighted. As a cultural symbol the chopsticks stand in importance next only to the dragon.
\end{abstract}

\section{Introduction}

Chopsticks play an important role in Chinese food culture. Chopsticks are called "Kuaizi" in Chinese. They were called "Zhu" in ancient times. Chinese people have been using Kuaizi as one of the main tableware for more than 3,000 years.

Our ancestors liked to steam or boil food. It was difficult for them to use spoons to dip vegetables in the soup. So they cleverly invented "Zhu" to nip food. Thus it has become the most convenient tableware in their lives. The invention of chopsticks involved a few scientifically theories. The lever principle of mechanics was applied to the use of chopsticks. The point at which two chopsticks cross is the pivot of the lever. In fact, they featured the coming of civilization to food culture.

\section{Chopsticks as a cultural symbol in China}

It was recorded in Liji(The book of Rites)that chopsticks were used during the Shang Dynasty(1600BC-1700BC)It was mentioned in Shiji(The Chinese history book)by Si Maqian (about 145BC)that Zhou, the lasting king of the Shang Dynasty (around 1100BC), used ivory chopsticks. Experts believe the history of wood or bamboo chopsticks can be dated back to about 1,000 years earlier than ivory chopsticks. Bronze chopsticks were invented in Western Zhou Dynasty (1100BC-771BC).Lacquered chopsticks from the Western Han Dynasty (206BC-24AD) were discovered in Mawangdui, China. Gold and silver chopsticks became popular in the Tang Dynasty (618-907).It was believed that silver chopsticks could detect poisons in food.

\section{Different materials of Chopsticks}

Chopsticks can be classified into several groups based on the materials used to make them, like wood, bamboo, metal, bone, stone and compound chopsticks. Nowadays, people's customers have changed. Bamboo and wood are more hygienic and hence it is sensible to use them.

\section{Some points regarding the use of chopsticks}

Chinese people are quite familiar with the use of chopsticks. Even from the age three years babies star using them. People that are very old also can use them. Thus the chopstick is not a mere of ornament but an eating aid having functional efficiency. There are some points regarding the use of chopsticks. First, we must hold the upper part and cross the chopsticks. Second, hold the chopsticks with the thumb, index finger, middle finger. Third, when we pick the food, use index finger and middle finger to control the chopsticks. Practice a lot and then we may find it is an easy job. Many foreigners are interested in but also puzzled about how to use chopsticks with facility. 


\section{A few things to avoid when using chopsticks}

Since we understand that the use of chopsticks has been a part of Chinese food culture. There are a few things to avoid when using chopsticks. Chinese people usually don't beat their bowls while eating, since this behavior is practiced by beggars. It's a better that we don't insert chopsticks in a bowl upright because it is a custom exclusively used in sacrifice.

\section{Chopsticks serve many new functions besides tableware}

Chopsticks also express the artistic and aesthetic sensibility of the Chinese people.

Tradition, it tells us that different colors and materials of chopsticks have specific meanings. They may stand for position, treasure, luck and so on.

For example, in Shang Dynasty, ivory was defined as the most valuable material as gold in modern day. So, when ivory chopsticks were invented in that period, only the King and Queen could afford use them. Silver chopstick which was quite necessary to detect poison in food

When bronze chopsticks were invented in Western Zhou Dynasty (1100BC-711BC), it's same to be valued as precious treasure. Ownership of bronze chopsticks lent one a stamp of prosperity, authority and status. And in later times, Gold and silver chopsticks were invented. Especially, it was mentioned earlier that silver chopsticks could detect poisons in food. Usually, in different Kungfu families, the masters always were very sensitive about tasting food in the odd inns. Because some enemies may have the deals with the inn to master poison them. In order to avoid being poisoned, the master always carried a single silver chopstick which was quite necessary to detect poison in food.

\section{Chopsticks those days played a glamorous role as well}

The chopsticks those days played a glamorous role as well. Beautiful ladies wore a silver and gold chopstick as part of their dressing. They used to put the colorful and smart silver or gold chopsticks on their bobs. The nobleness, razzmatazz, wealth, were all reflected from such eastern beauties. This kind of fashion was also used in Beijing Olympic Games in 2008.

Evermore, 'Chopsticks' reads 'Kuaizi' which means to have sons soon in China. So a newly-married couple will be very happy to accept chopsticks as their wedding gift. Skilful craftsmen painted beautiful sceneries on chopsticks to make them fine artworks. Many people love to collect these dainty chopsticks as their treasure.

\section{Chopstick Theory}

Chopsticks are small but they are adored by many people in the world. An interesting experiment shows that many joints and muscles are being exercised when we use chopsticks. They certainly make us clever, don't they?

It is said that $85 \%$ of people use chopsticks with right hand, $10 \%$ of people use chopsticks with left hand, and another5\% people can use chopsticks with both hands. It is held that people using chopsticks with their left hand are cleverer than the others. Those who use both the hands are exceptional people--genius.

As a cultural symbol the chopsticks stand in importance next only to the Dragon

The Chinese people advocate unity. It is a value but is imparted in family education. To achieve these parents used the 'Chopstick Theory 'with demonstration. If you take a single chopstick, it is easy to break. But take ten, it becomes impossible. One single chopstick stands for one man, ten pairs of people stand for togetherness, unity and strength. When we talk about 'Chopstick Theory', we may pay our respect to our ancestors once more. As a cultural symbol the chopsticks stand in importance next only to the Dragon.

\section{Conclusion}

Now let me conclude my paper by answering why I have chopsticks as my subject and not some piece of poetry or fiction. What is literature? It is a mode of thinking by which we capture our experiences. Experiences and thoughts on them are crucial in cultural making. We, as human beings, make culture and then find ways to express it. And I think I am convinced that the chopsticks serve identical functions in the Chinese content. Hence I attempt at describing and explaining cultural significance of "CHOPSTICKS". And without doubt "chopsticks "represent and express so much of the Chinese culture and people. Chopsticks are the living principle in the hearts and minds of the Chinese people.

\section{Work Cited:}

[1]. http://www.kwintessential.co.uk/articles/china/chinese-culture-symbols/1783

[2]. http://kaleidoscope.cultural-china.com/en/8Kaleidoscope122.html 